\title{
THE FIRST FORECASTERS' HANDBOOK FOR WEST AFRICA
}

\author{
Rosalind Cornforth, Douglas J. Parker, Mariane Diop-Kane, Andreas H. Fink, \\ Jean-Philippe Lafore, Arlene Laing, Ernest Afiesimama, Jim Caughey, Aida Diongue-Niang, \\ Abdou Kassimou, Peter Lamb, Benjamin Lamptey, Zilore Mumba, Ifeanyi Nnodu, \\ Jerome Omotosho, Steve Palmer, Patrick Parrish, Leon-Guy Razafindrakoto, \\ Wassila ThiaW, Chris Thorncroft, and Adrian TOMPKINS
}

Meteorology of Tropical West Africa: The Forecasters' Handbook is set to change the way forecasters, researchers, and students learn about tropical meteorology and will serve to drive demand for new forecasting tools.

D aily weather patterns directly influence human survival in Africa more so than in any other well-populated continent. Furthermore, West Africa currently exhibits one of the largest population growths on Earth, with many emerging megacities that are prone to urban flooding from very intense convective events. Despite this, 24-h quantitative precipitation forecasts for West Africa often have no additional skill when compared to climatology in operational ensemble forecasts from global numerical weather predication models (Vogel et al. 2018). Indeed, weather forecasting and "nowcasting" for the region has in recent years fallen behind relative to other parts of the world.

To advance the scientific understanding of the weather and climate of West Africa and its human interactions, the African Monsoon Multidisciplinary Analysis (AMMA; www.amma-international.org) (Redelsperger et al. 2006; Polcher et al. 2011; Lebel et al. 2011) was launched in the spring of 2002 with funding from France (in 2002), the United Kingdom (in 2004), the European Commission (in 2005), and the United States (in 2005). It was the largest program of research into the African environment and climate ever attempted. An overarching goal of the project was to ensure that the multidisciplinary research was effectively integrated with prediction and decision-making activity, and AMMA has thus been deeply rooted in the realities of operational methods in the region (Fink et al. 2011). Part of AMMA's legacy was the activation of a remarkable community of researchers and forecasters from Africa and around the world. By continuing to work together, this community has since produced a landmark document, describing the state-of-the-art in weather prediction for tropical and subtropical West Africa and updating forecasting techniques.

Meteorology of Tropical West Africa: The Forecasters' Handbook utilizes the new weather and climate research from AMMA and makes this applicable to forecasting. Through its sponsorship by the World Meteorological Organization, and its publication as a textbook in 2017, the methods and tools will be made available to the operational prediction community in West Africa; to early-career researchers; to summer school participants such as those with the Ewiem Nimdie (Tompkins et al. 2012; Danuor et al. 2011), started in AMMA; and to future generations of undergraduate and graduate students of meteorology and related fields from all over the globe. 
KEY ELEMENTS. Our overall aim in developing The Forecasters' Handbook was to synthesize the latest knowledge of African meteorology with operational tools and methodologies for improving weather forecasting in West Africa. One specific objective was to transfer new insights into the dynamics of West African weather systems, which emerged from recent international research efforts such as AMMA, into operational forecasting (Polcher et al. 2011; Fink et al. 2011). There is surprisingly little documented text regarding tropical forecasting, and almost nothing written about West African meteorology outside of scientific papers. The Forecasters' Handbook therefore sets out to make optimum use of the rapidly moving research in this area, and to move African meteorology forwards as quickly as possible.

A second objective was to summarize the recent status of understanding of West African weather and climate systems across scales, from planetary to local (see, e.g., Lebel et al. 2010). As a consequence, The Forecasters' Handbook is presented in a textbook style, with each chapter starting with the scientific background, followed by operational methods. A series of case studies provided by Météo-France are also available and updated in the online version (see Table 1), enhancing understanding of the potential application of methods. A third objective was to produce a physical book. The reason for this was that while there is a diversity of resources available to forecasters in the region, only a number of National Hydrological and Meteorological Services (NHMS) have access to sophisticated data products and tools in their main forecasting centers [e.g., Ghana Meteorological Agency (GMA), Accra,
Ghana; Agence Nationale de l'Aviation Civile et de la Météorologie (ANACIM), Dakar, Senegal; African Centre of Meteorological Application for Development (ACMAD), Niamey, Niger], while many of the provincial offices work in isolation and without access to the Internet. There was, therefore, a real need to create a traditional, printed handbook to be used as a reference guide that forecasters can refer to when they need to check details of thresholds or examples of a phenomenon.

To produce The Forecasters' Handbook, formal governance structures were put in place at the outset, in order to generate ownership, provide credibility, and build the sustainability of this resource. Key partners to achieve this included ACMAD and the World Meteorological Organization (WMO).

The editorial committee ${ }^{1}$ provided strategic guidance on the project throughout. Working with the editors, the committee developed the overall structure and content and approved and invited chapter authors and other consultants.

The lead authors were both researchers and forecasters, ensuring the inclusion of the relevant latest content, and they were able to involve a wide group of "contributors" for each chapter comprising

\footnotetext{
${ }^{1}$ Editorial committee: Douglas J. Parker (Chair), Ernest Afiesimama, Jim Caughey, Rosalind Cornforth, Mariane Diop-Kane, Aida Diongue-Niang, Andreas H. Fink, Ibrahima Hamza (EAMAC), Jean-Philippe Lafore, Arlene Laing, Peter Lamb, Benjamin Lamptey, Zilore Mumba, Ifeanyi Nnodu, Jerome Omotosho, Steve Palmer, Wassila Thiaw, Chris Thorncroft, and Adrian Tompkins.
}

AFFILIATIONS: CORNFORTH-Walker Institute, University of Reading, Reading, United Kingdom; PARKER-School of Earth and Environment, University of Leeds, Leeds, United Kingdom; Diop-Kane AND DIONGUe-NIANG-Agence Nationale de l'Aviation Civile et de la Météorologie du Sénégal (ANACIM), Dakar, Senegal; Fink - Institute of Meteorology and Climate Research, Karlsruhe Institute for Technology, Karlsruhe, Germany; LAFORE-Météo France, and CNRS, Toulouse, France; LAING-Cooperative Institute for Research in the Atmosphere, Colorado State University, Fort Collins, Colorado; Afiesimama AND NNOdU-Nigerian Meteorological Agency (NiMET), Abuja, Nigeria; CAUGHEY - THORPEX International Programme Committee, World Meteorological Organization, Geneva, Switzerland; Kassimou—Direction de la Météorologie Nationale, Niamey, Niger; LAMB*_Cooperative Institute for Mesoscale Meteorological Studies, and School of Meteorology, University of Oklahoma, Norman, Oklahoma; LAMPTEY AND RAZAFINDRAKOTOAfrican Centre of Meteorological Applications for Development, Niamey, Niger; Mumba-Department of Mathematics and Statistics, University of Zambia, Lusaka, Zambia; Омотоsно-School of Earth and Mineral Sciences, Federal University of Technology, Akure, Nigeria; PARRISH-Training Activities Division, Education and Training Office, World Meteorological Organization, Geneva, Switzerland; PALMER-Met Office Hadley Centre, Exeter, United Kingdom; THIAW-NOAA Center for Weather and Climate Prediction, College Park, Maryland; THORNCROFT-University at Albany, State University of New York, Albany, New York; ToMPKINS-Abdus Salam International Centre for Theoretical Physics, Trieste, Italy * Deceased. CORRESPONDING AUTHOR: Rosalind Cornforth, r.j.cornforth@reading.ac.uk

The abstract for this article can be found in this issue, following the table of contents.

DOI:I0.II75/BAMS-D-16-0273.I

In final form 19 November 2018 (C)2019 American Meteorological Society

For information regarding reuse of this content and general copyright information, consult the AMS Copyright Policy. 
operational forecasters and other specialists in West African forecasting. A vital piece of the puzzle was including members of the African Meteorological Services, who were able to commit their time and were fully supported by their organizations.

HANDBOOK STRUCTURE. To help build vital capacity and enable NHMS to develop practical applications from weather and climate research that can support resilient strategies (Boyd et al. 2013) on the ground, each chapter in The Forecasters' Handbook is split into two parts: 1) scientific background and literature and 2) operational methods. Some chapters also include a final section of "Case studies and learning resources"; additional case studies have been provided in the online supplement to The Forecasters' Handbook.

This layout means that The Forecasters' Handbook can be used for self-study. We describe pragmatic approaches to forecasting, including, for example, the plotting of synoptic charts from regional observations and the computation of stability indices from upper-air data. Working together, forecasters and researchers have generated canonical figures for typical synoptic situations, thereby translating the science to specific forecasting tools. The case studies help to close the gap between research and user applications through relevant examples (see Table 1), and with this in mind, explicit attention has been given to useful graphical and presentational formats for forecast dissemination.

The Forecasters' Handbook has been deliberately designed to provide a logical flow from large scales to the local level, with forecasters in mind as they are working at their posts. A summary of a number of the key themes in each chapter follow below.

The Forecasters' Handbook begins by discussing the mean climate and seasonal cycle of West Africa (chapter 1; see Fig. 1) based on new observations made during AMMA, including traditional in situ ground and upper-air observations, a state-of-the-art reanalysis, and a variety of satellite-derived maps. Focus is on the hydrologic cycle, including clouds, surface, and upper-air circulations, as well as the climatologies of African easterly waves (AEWs). The complex climate system over West Africa is synthesized in a map and meridional cross section. This builds on the classic four-weather-zones concept (see Fig. 1), and chapter 1 is likely one of the most complete and up-to-date climate references for the West African monsoon (WAM) region.

Discussion of mean climate then flows to synoptic systems (chapter 2) in which many of the convective rainfall events in the WAM are embedded. AMMA has brought about considerable progress in the understanding and modeling of such systems. Prime examples are AEWs and their diversity, as they appear on daily weather maps. There are many cases where important scientific ideas need to be known by forecasters but are not necessarily coupled to specific forecasting tools. For instance, all forecasters should know about the current understanding of AEWs, but this is not always easily translated into forecast parameters such as rainfall, winds, or visibility. Figure 2 is a new consensus schematic of these various 
observable parameters and likely relationships. It was forged through many lengthy and animated conversations between researchers and forecasters, exemplifying the transfer of new insights into the dynamics of West African weather systems [e.g., a precipitable water perspective, its relationship with mesoscale convective systems (MCSs), and its translation into operational forecasting]. The chapter also discusses tropical-extratropical interactions that are important in the dry and transition seasons. Also included are schematic depictions of the large-scale circulation associated with dry-season precipitation over West Africa linked to low-latitude upper-level disturbances from the extratropics.

The deep convective systems that provide the bulk of the rainfall in West Africa (chapter 3) range from isolated cells to huge organized MCSs, with new research from AMMA explaining how they are triggered. The type of convection depends on the ambient profiles of vertical wind shear and humidity distribution. Midlevel dry layers are pivotal in the creation of deep convective density currents, which in turn favor organization and longevity of convection.

Moving through the atmospheric scales as the chapters advance, the phenomena that shape the local weather (chapter 4) are discussed in the next chapter. West Africa is a region where the population is particularly vulnerable to local patterns of precipitation, temperatures, and winds, and these fields are also critical for vital sectors such as aviation, agriculture, or healthcare; thus, local weather prediction is particularly important for the forecaster. The chapter brings new research from AMMA into forecasting, such as the dependence of measures of daily maximum/minimum temperatures on soil moisture and new observations of wind shear in the (a)
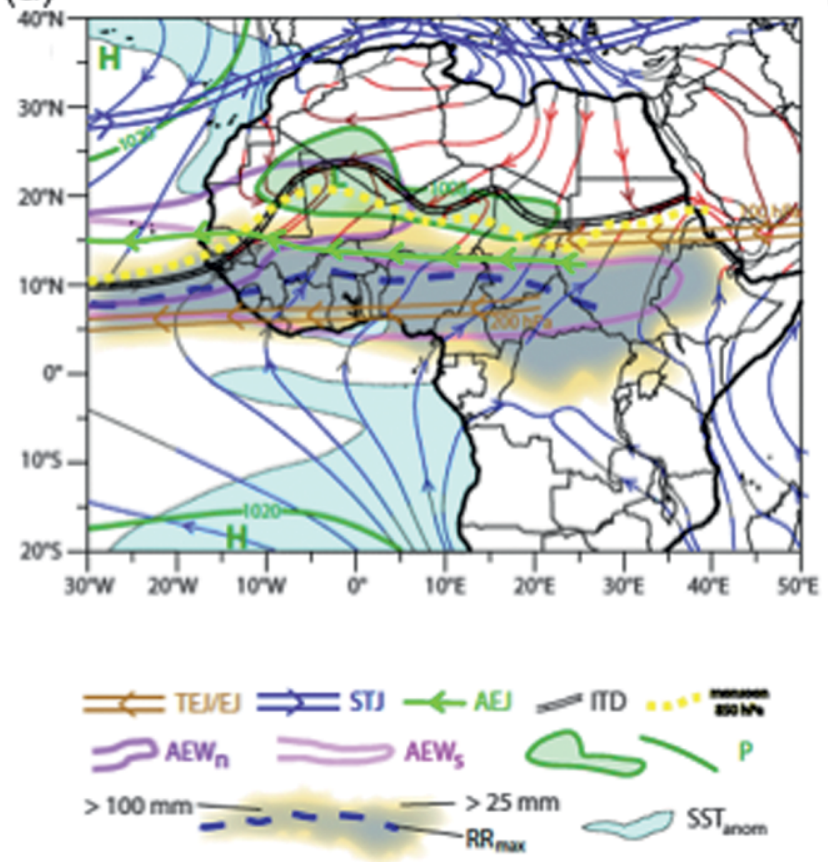

(b)

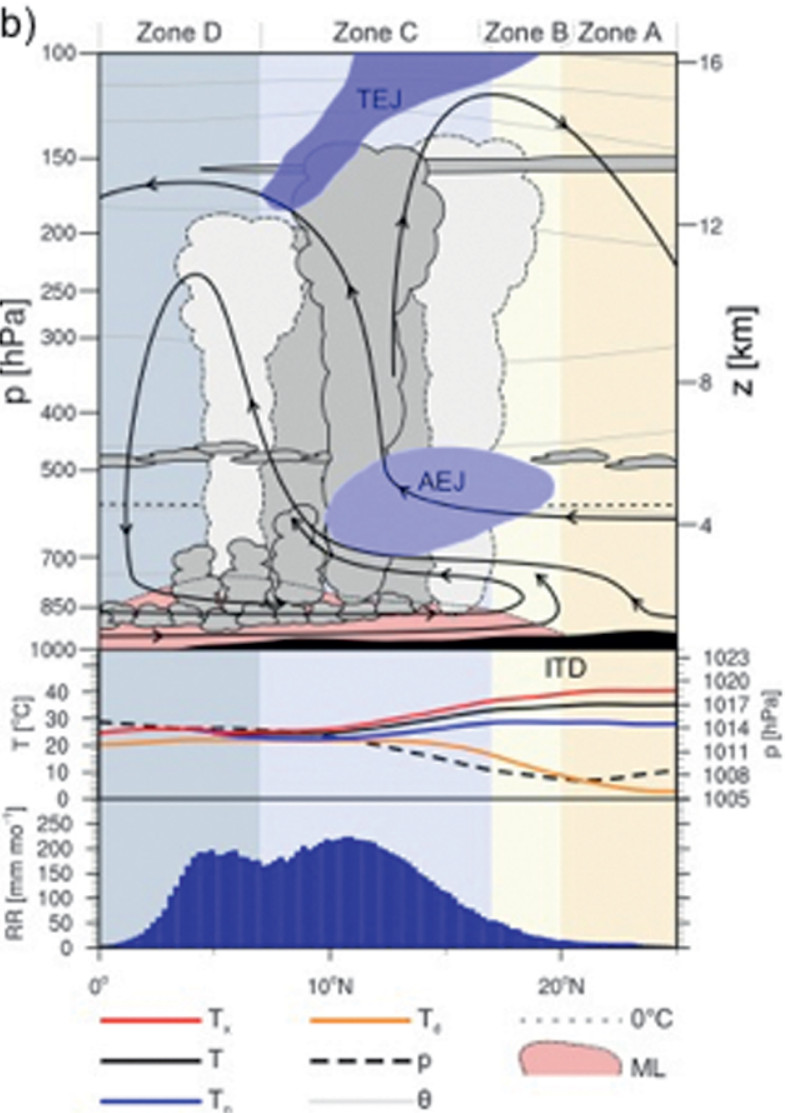

FIG. I. The WAM in July, depicted in (a) a map showing the major climate features and (b) a north-south meridional cross section between $10^{\circ} \mathrm{W}$ and $10^{\circ} \mathrm{E}$ with classical weather zones A-D. Shown are positions of the intertropical discontinuity [ITD, also known as the intertropical front (ITF)]; upper-level jet steams [AE], tropical easterly jet (TEJ)/easterly jet (EJ), and subtropical jet (STJ)]; the monsoon layer (ML; as defined by westerly or positive zonal winds); streamlines; clouds; the freezing level $\left(0^{\circ} \mathrm{C}\right.$ isotherm); isentropes $(\theta)$; minimum $\left(T_{n}\right)$, maximum $\left(T_{x}\right)$, mean $(T)$, and dewpoint $\left(T_{d}\right)$ temperatures; atmospheric pressure $(p)$; and mean monthly rainfall totals (RR). The weather zones (A-D) denote regions of specific and very different weather across the WAM as described by Hamilton et al. (1945) in their conceptual model. 
lower boundary layer. Topics discussed include gravity waves, inertial oscillations, land-sea breezes and related cloudiness, winds and convective initiation related to land surface characteristics, surface energy fluxes, low-level shear, and fog.

A critical forecasting element influencing both synoptic and local conditions in West Africa is dust (chapter 5). This phenomenon is tackled from different perspectives, explaining the physics of dust uplift in different meteorological conditions, and using these ideas to show how certain synoptic conditions can induce dust-generating winds over wide regions, as well as over a number of days. Key thresholds and observational criteria for forecasting dust and associated visibility are tabulated.

New knowledge about convective storms, local severe weather, and dust storms come together in the discussion of nowcasting (chapter 6). In preparing this material, it became apparent that systematic methodologies for nowcasting in West Africa are lacking. A general perspective on nowcasting principles, methods, and operational practice are thus given, underpinned with examples from the Americas as well as from West Africa. Despite the current lack of nowcasting know-how, the longevity of the region's MCSs (which can persist and propagate for many hours) gives optimism that nowcasting methods can in the future produce useful alerts and advisories for severe weather. As there are only a few radars that are operational in the region, emphasis is placed on the ways in which nowcasting can exploit satellite remote sensing products. This field is clearly one in which more research is needed in the region in order to develop climatologies, conceptual models, case studies, and quantitative tools.

AMMA has shown that MCSs and convective activity are modulated not only by synoptic systems like African easterly waves, but also at longer
2
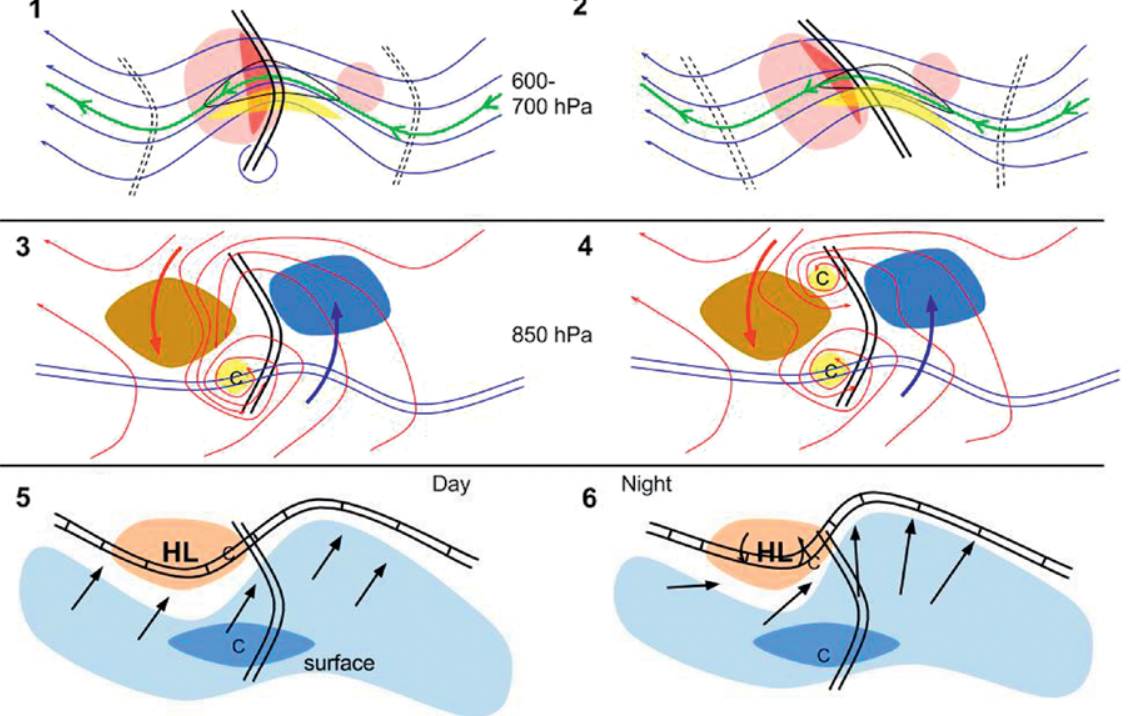

6 Night
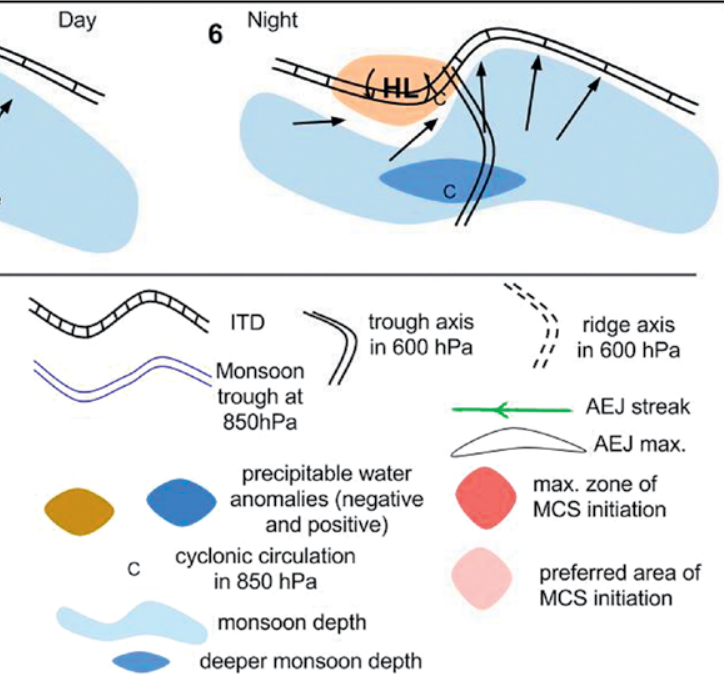

FIG. 2. Schematic of the various observable elements of an AEW and likely relationships between these. The left-hand panels show a "normal" situation, as far as this exists, while the right-hand panels show common alternatives.

intraseasonal time scales (10-90 days). These subseasonal modes of variability are mostly controlled by convectively coupled equatorial waves, midlatitude atmospheric intrusions, as well as the Madden-Julian oscillation (MJO). They influence the onset of the rainy season and have an important impact on agricultural yields in the Sahel. The progress made in subseasonal forecasting (chapter 7) emphasizes the skill of weather prediction at lead times of 1-14 days, and there exists genuine potential in at least week-1 and week-2 forecasts.

Transitioning from subseasonal to seasonal prediction time scales (chapter 8), The Forecasters' Handbook reviews and explains the blend of statistical and numerical methods that are currently used to deliver guidance and advisories in the region. Examples of specific impact-focused seasonal forecasting efforts, in regard to water resources, agriculture, and meningitis prediction, are used to illustrate the methods.

The next chapter of The Forecasters' Handbook introduces the reader to all kinds of satellite sensors (chapter 9), which are an inevitable and growing 
source of information in a ground and upper-air data-sparse region. The lead author also led the COMET online tropical meteorology textbook (www.meted.ucar.edu) development, and this is reflected in a scholarly review on the use of more classical (e.g., visible, infrared, and water vapor images) and advanced (e.g., RGB multichannel composites, spaceborne microwave, and radar products) satellite information.

Clearly, any survey of forecasting methods must address the topic of numerical weather prediction (NWP; chapter 10): know-how and training in this area is one of the highest demands among West African forecasters, and the field of NWP is moving forward rapidly. The next generation of convection-permitting models may in the near future offer the chance to deliver more reliable local-scale predictions. The fundamentals of NWP, including the basic equations solved, the essentials of various parameterization schemes, and the principles of data assimilation and ensemble prediction, and examples of the use of NWP in operational forecasting link the material back to questions of synoptic and local prediction, as well as nowcasting.

An exciting development in AMMA was the creation and interpretation of the West African Synthetic Analysis and Forecast (WASA/F; chapter 11) maps that emerged from the 2006 ground campaign. The maps synthesize the major weather features, such as the monsoon trough, African easterly jet (AEJ), and the troughs and cyclonic centers associated with AEWs on an analysis and a forecast map, which helps forecasters capture complex weather situations at a glance. The WASA/F maps continue to be produced operationally at ACMAD and le Centre
Interarmées de Soutien Météo-océanographique aux Forces (CISMF) by Météo-France forecasters. The 10 key features that are included in the WASA/F are shown in Fig. 3.

Mindful that The Forecasters' Handbook is both a reference guide and a learning resource, online training materials have been made available in both English and French. This includes the case studies, as well as the ability for users to visualize selected maps and obtain scholarly explanations in both languages (see www.umr-cnrm.fr/waf_handbook_casestudies). Further to this, The Forecasters' Handbook was fully translated into French, published and made available in July 2018 (online at https://laboutique.edpsciences .fr/produit/I038/978275982I808/Meteorologie\%20 de\%20IAfrique\%20de\%20lOuest\%20tropicale), with 165 French copies distributed across West Africa.

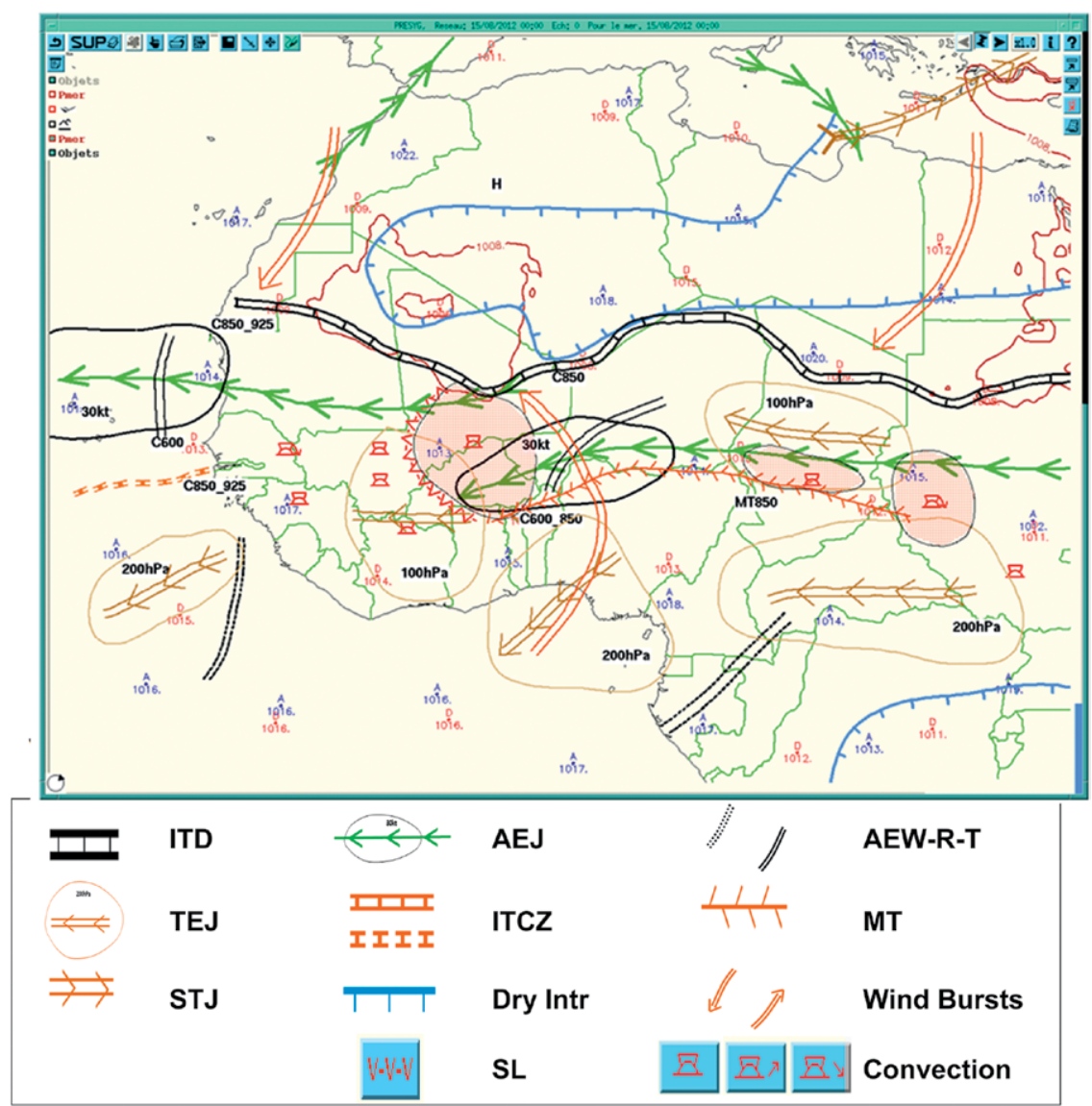

Fig. 3. An example of the WASA/F map developed in AMMA in 2006 and now used operationally at ACMAD. Ten key features included in the WASA/F are I) ITD, 2) heat low, 3) STJ, 4) trough from midlatitude, 5) TEJ, 6) AEJ, 7) troughs and cyclonic centers (C) associated with AEWs, 8) midlevel dry intrusions, 9) monsoon trough (MT), and 10) convective activity-suppressed convection and isolated MCSs [e.g., squall lines (SL)]. The pressure levels at which varying features reside are denoted, for example, "C600" means the cyclonic center associated with an AEW at $600 \mathrm{hPa}$ and "MT850 refers to the monsoon trough at $850 \mathrm{hPa}$. 
CHALLENGES. From first inception to completion, The Forecasters' Handbook has taken 10 years of work. The decade has been driven by debate, as much as by a commonly held desire to make a difference-to transfer insight and summarize our mutual understanding for the benefit of future generations. Notable challenges have been in reaching consensus against a background of basic differences of perspective between researchers, NWP providers, and bench forecasters, and in sustaining momentum among a community of scientists and operational specialists without specific funding for the work.

Basic differences in perspective have been a common theme throughout the project. One example of this was in forecasters' use of $850-\mathrm{hPa}$ charts to locate the depth, northward extension, and organization of monsoon inflow and the presence and locations of vortices and convergence lines. Researchers had neglected this important level, because they had focused on the theoretical dynamics of interactions between waves at the surface and the jet level of $650 \mathrm{hPa}$. This made clear the importance of making space for dialogue between both researchers and forecasters. At times, both communities displayed conservatism and were unwilling to abandon their accepted ideas and untested methods. For example, researchers were unwilling to accept that AEW troughs are commonly observed by forecasters to tilt downshear, while forecasters were reluctant initially to abandon their use of divergence and convergence fields in rainfall prediction. Another example came from the realization that fog is a common high-impact phenomenon in the region, for which more research is needed. Indeed, responding to this particular challenge threw into sharp relief the balance that had to be struck between the latest science and finding pragmatic solutions in often resource-poor environments. Ultimately, untested methods were included in The Forecasters' Handbook, if there was demonstrated success in another part of the world. An example of this would be the use of the temperature and humidity data for evaluation of the human impact of extreme temperatures, where the methodology comes from the United States. This approach ultimately will enable forecasters to perform the necessary testing for their region.

\section{MOVING FORWARD: TOP IO SUGGESTED} RESEARCH DIRECTIONS. The closing of this chapter of work from AMMA inevitably opens the door to the next. Together, the community has identified research areas to focus on that are driven by the needs of forecast operations and users-those with a shorter time horizon for realizing improvements in forecasting. These include the following:

1) Better understanding of other African regionscoastal regions, central Africa, and the eastern Sahel as a source of intraseasonal variability affecting West Africa.

2) Further study of the forcing by, and interactions with, midlatitude and equatorial waves, and the Indian monsoon.

3) Extending research to other seasons, in particular, spring and the corresponding heat waves, and to the pre-onset of the monsoon.

4) Coupling with the ocean, in particular, cold tongue development and its impact on the monsoon.

5) More attention on radiation processes, clouds, and aerosols-because these are needed to improve models for the region.

6) More research on maximum and minimum temperatures, and their links to synoptic and aerosol environments.

7) More research into climatology and the dynamics of fog.

8) Development of region-specific nowcasting procedures. These must take into account the different observational and model data available, notably the lack of radars and the need to use high-frequency geostationary images. A suggested entry point might be through leveraging and collaborating with the European Organisation for the Exploitation of Meteorological Satellites (EUMETSAT) and the COMET Program, part of the University Corporation for Atmospheric Research's (UCAR) Community Programs. Both EUMETSAT and COMET have a long record of training through the African Satellite Meteorology Education and Training (ASMET) program.

9) Need for more and better-validated conceptual models to inform interpretation, nowcasting, and forecast communication. Notably, better synoptic models for the situations leading to extreme rainfall or drought, such as breaking AEWs or dry intrusions.

10) Exploitation of (i) convective-scale NWP and (ii) ensembles, especially at the convective scaleneed to deal more in depth with ensemble techniques that are as of yet of modest value for West Africa due to the very poor skill of models in the region.

In addition to the research required going forward, The Forecasters' Handbook should be embedded 
into training programs for forecasters in the region. Sustainability would be enhanced through linking these into capacity-building activities integrated into the implementation of the Global Framework for Climate Services for the Sahel through country-driven National Action Plans. By having a common reference, it is intended that good practice across the region can be shared, and that future improvements in practice are completed against a common understanding. Plans are already going ahead to use The Forecasters' Handbook to support training activities in the l'École Africaine de la Météorologie et de l'Aviation Civile (EAMAC) regional centers at Lagos and Niamey, and in international training, for instance, supporting the WMO's Severe Weather Forecasting Demonstration Project (SWFDP) West African program.

Finally, the success of The Forecasters' Handbook project has raised questions around whether similar material can be collected for other areas, such as East Africa. The African Science for Weather Information and Forecasting Techniques, funded in 2017 by the U.K.'s Global Challenge Research Fund (GCRF), will provide resources over a period of 4 years to support training initiatives making use of The Forecasters' Handbook, and will extend the material to the East African region.

TIMELINESS. Given the notable trend emerging in science applications worldwide that increase the emphasis on the need to provide "climate services" (Lamb et al. 2011), the production of The Forecasters' Handbook ensures that for the first time ever, there is long-term documentation of robust, reliable, and up-to-date scientific weather forecasting methods available to the operational prediction community in West Africa. The 2018 publication of a French translation of The Forecasters' Handbook will undoubtedly help to spread its use in the Francophone West African countries. Its preparation has helped to sustain partnerships between forecasters and African researchers. Its legacy includes the sharing of existing good practice made possible in Africa and elsewhere, and the development of new tools, new methods, and new data sources for forecaster training and wider meteorological education. Dialogue, ownership, and co-development were pioneering elements for overcoming multiple barriers and bringing The Forecasters' Handbook to completion. This coproduction approach now underpins the effective delivery of climate services not only across West Africa, but across the world. The Forecasters' Handbook provides a means to link the producers (the African weather services) with the user community of decision-takers (e.g., aviation, agriculture, industry, humanitarian, and development practitioners) and decision-makers (government and policy-makers). Above all, the production of The Forecasters' Handbook for West Africa demonstrates that research and forecasting knowledge, held by a dispersed community of people with different perspectives and priorities, can be brought together effectively to address climate challenges. We can only become truly resilient to changes in climate if we improve our capacity to respond in partnership. By bringing together, at the outset, researchers and forecasters from across the region, and linking to applications, user communities, and decision-makers, The Forecasters' Handbook provides a template for finding much-needed solutions to critical issues such as building resilience to weather hazards and climate change in West Africa.

ACKNOWLEDGMENTS. This article is dedicated to the memory of the late Professor Peter Lamb, a great friend to Africa, our much honored and loved colleague, veritable coauthor, and founder of RAINWATCH (www.rainwatch-africa.org), who contributed so much to the understanding of African climate variability, seasonal forecasting, and to educational outreach "to help Africa to help itself" (Tarhule et al. 2009). The development of The Forecasters' Handbook reported in this paper is an international joint effort arising from the international African Monsoon Multidisciplinary Analysis (AMMA) project. Most of the funding for the supporting workshops hosted in Leeds (October-December 2012) and in Dakar (18-21 March 2013) was provided by NERC, through the AMMA-U.K. consortium (NERC NE/B505538/1), through the Africa Climate Exchange (AfClix) Knowledge Exchange Fellowship (NERC NE/J50063X/1), the WMO, and ACMAD. The authorship of this article represents the steering committee: many other people made substantial contributions to the development of The Forecasters' Handbook. We thank Nicolas Chapelon and Volker Ermet for their considerable technical support in providing diagnostics for the case studies and generating figures throughout. We thank Florence Favot for the development of the "Case Studies" website (www.umr-cnrm.fr /waf_handbook_casestudies). We are grateful to ACMAD for participating in the Dakar workshop, providing their technical expertise, some of the required data, assistance with the figures, and understanding of NHMS practices. Katiellou Lawan Gaptia and Moussa Mouhaimouni also kindly helped familiarize us with NHMS operations. It is also a pleasure to acknowledge the recognition awarded to The Forecasters' Handbook by the Atmospheric Science Librarians International (ASLI) and receipt of the 2017 
ASLI Choice Prize "for bringing together the science of climate, weather and forecasting that many will reference as they work in and with this important geographical area," presented at the thirteenth annual ASLI Choice Awards in Austin, Texas, during the 98th Annual AMS Meeting (see www.aslionline.org/wp/2017-asli-choice-awards -winners/). Funding and other support we gratefully acknowledge from ACMAD; AMMA and its component programs (AMMA-EU, AMMA-U.K., AMMA-France, RIPIECSA); WMO; WWRP/THORPEX; Natural Environment Research Council (NERC); Météo-France/CNRM and for their further contribution of $€ 30,000$ in 2018 to fund the French publication of The Forecasters' Handbook; the Met Office; University of Leeds; Walker Institute; University of Reading, ANACIM; International Centre for Theoretical Physics; Royal Meteorological Society; the American Meteorological Society; and the Royal Society; and the very many contributors to the chapters.

\section{REFERENCES}

Boyd, E., R. J. Cornforth, P. J. Lamb, A. Tarhule, M. I. Lélé, and A. Brouder, 2013: Building resilience to face recurring environmental crisis in African Sahel. Nat. Climate Change, 3, 631-637, https://doi.org/10.1038 /nclimate1856.

Danuor, S., and Coauthors, 2011: Education in meteorology and climate sciences in West Africa. Atmos. Sci. Lett., 12, 155-159, https://doi.org/10.1002/asl.326.

Fink, A. H., and Coauthors, 2011: Operational meteorology in West Africa: Observational networks, weather analysis and forecasting. Atmos. Sci. Lett., 12, 135-141, https://doi.org/10.1002/asl.324.

Hamilton, R. A., J. W. Archbold, and C. K. M. Douglas, 1945: Meteorology of Nigeria and adjacent territory. Quart. J. Roy. Meteor. Soc., 71, 231-264, https://doi .org/10.1002/qj.49707130905.
Lamb, P. J., R. P. Timmer, and M. I. Lélé, 2011: Professional development for providers of seasonal climate prediction. Climate Res., 47, 57-75, https:// doi.org/10.3354/cr00949.

Lebel, T., and Coauthors, 2010: The AMMA field campaigns: Multiscale and multidisciplinary observations in the West African region. Quart. J. Roy. Meteor. Soc., 136, 8-33, https://doi.org/10.1002/qj.486.

- , and Coauthors, 2011: The AMMA field campaigns: Accomplishments and lessons learned. Atmos. Sci. Lett., 12, 123-128, https://doi.org/10.1002/asl.323.

Polcher, J., and Coauthors, 2011: AMMA's contribution to the evolution of prediction and decision-making systems for West Africa. Atmos. Sci. Lett., 12, 2-6, https://doi.org/10.1002/asl.320.

Redelsperger, J.-L., C. D. Thorncroft, A. Diedhiou, T. Lebel, D. J. Parker, and J. Polcher, 2006: African Monsoon Multidisciplinary Analysis: An international research project and field campaign. Bull. Amer. Meteor. Soc., 87, 1739-1746, https://doi .org/10.1175/BAMS-87-12-1739.

Tarhule, A., Z. Saley-Bana, and P. J. Lamb, 2009: Rainwatch: A prototype GIS for rainfall monitoring in West Africa. Bull. Amer. Meteor. Soc., 90, 1607-1614, https://doi.org/10.1175/2009BAMS2697.1.

Tompkins, A. M., and Coauthors, 2012: The Ewiem Nimdie summer school series in Ghana: Capacity building in meteorological education and researchLessons learned and future prospects. Bull. Amer. Meteor. Soc., 93, 595-601, https://doi.org/10.1175 /BAMS-D-11-00098.1.

Vogel, P., P. Knippertz, A. H. Fink, A. Schlueter, and T. Gneiting, 2018: Skill of global raw and postprocessed ensemble predictions of rainfall over northern tropical Africa. Wea. Forecasting, 33, 369-388, https://doi.org/10.1175/WAF-D-17-0127.1. 


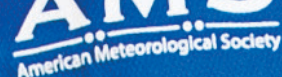

\section{AMS}

